This document is the accepted manuscript version of the following article:

Cherunya, P. C., Truffer, B., Samue1, E. M., \& Lüthi, C. (2020). The challenges of

livelihoods reconstruction in the context of informal settlement upgrading.

Environment and Planning A. https://doi.org/10.1177/0308518X20926514

\title{
The challenges of livelihoods reconstruction in the context of informal settlement upgrading
}

Pauline C. Cherunya*,a,b, Bernhard Truffer a,b, Edinah Moraa Samuel c, Christoph Lüthi d

a Department of Environmental Social Sciences, Eawag, Überlandstrasse 133, CH-8600 Dübendorf, Switzerland

${ }^{\mathrm{b}}$ Copernicus Institute of Sustainable Development, Utrecht University, Princetonlaan 8a, 3584 CB Utrecht, The Netherlands

c Department of Environmental Planning and Management, Kenyatta University, Nairobi, Kenya

d Department Sanitation, Water and Solid Waste for Development, Eawag, Überlandstrasse 133, CH-8600 Dübendorf,

Switzerland

* Corresponding author

Department of Environmental Social Sciences,

Eawag: Swiss Federal Institute of Aquatic Science and Technology,

Ueberlandstrasse 133, 8600 Duebendorf, Switzerland.

Email address: pauline.cherunya@eawag.ch

\section{Abstract}

Community involvement is recognised as a core condition for success in informal settlements upgrading. However, the wider ramifications of this requirement are not well understood. Mostly, community involvement has been equated with a narrow interpretation of participation, largely focusing on the elicitation of dwellers' preferences at the planning stages. We argue that this approach overlooks the actual needs for livelihoods reconstruction in the course of upgrading. To better conceptualize these requirements, we propose to analyse the time-space configuration of practices, which we frame as constituting Oscillating Domestic Spaces. The concept illustrates the contingent nature of daily activities to meet livelihoods needs and how people navigate these conditions. Challenges associated with reconstructing new domestic spaces are illustrated using the Kenyan Slum Upgrading (Kensup) initiative in Nairobi, Kenya. The findings suggest that an inadequate understanding and consideration of livelihoods reconstruction reduced legitimacy of the initiative, resulted in rapid deterioration of physical amenities, and relegated most of the alleged "beneficiaries" deeper into poverty. We suggest that, for successful settlements upgrading, livelihoods reconstruction should be a core process in the planning, implementation and post-implementation stages.

Keywords: Informal settlement upgrading, Oscillating Domestic Space, participation, livelihoods reconstruction, relocation. 


\section{Introduction}

According to the United Nations, more than one billion people live in informal settlements of the world's cities, and by 2050 the population is expected to grow to more than three billion if the current trends persist (UN-DESA, 2018). Dwellers of these settlements often lack security of tenure for the land or dwellings they inhabit. They also lack basic services and the settlements are often situated in geographically and environmentally sensitive areas, leaving residents vulnerable to disasters and diseases (UN-Habitat, 2015; Corburn and Sverdlik, 2019). Settlement dwellers, therefore, live in anxiety and are deprived of safe, healthy and dignified conditions for living. As such, informal settlements upgrading and preventing the establishment of new ones has become a priority in global sustainable development agendas (UN-DESA, 2018).

In over half a century, informal settlements upgrading has been undertaken by state and non-state actors in Asia, Africa and Latin America (Gulyani and Bassett, 2007). The approaches consist of economic, social, institutional, and community interventions (Cities-Alliance, 2019). At the community level, upgrading essentially entails planned reordering of urban housing and infrastructures to improve service access and to enhance hygiene and aesthetics (Fullilove, 2016: 52). The envisioned transformations are expected to improve conditions for daily living at the household level, and as well create positive outward effects for the community and society at large. Despite a lot of efforts in Global South cities to upgrade settlements, actual experiences have shown sobering results where projects have failed to produce benefits for the so-called "beneficiaries"1. Problems of politicization, corruption, poor coordination, lack of participation, complexity of evaluation techniques, weak financial mechanisms, weak performance of formal institutions, tenure rights, and social conflicts are suggested to impede successful upgrading (Abbott et al., 2001; Gulyani and Bassett, 2007; Imparato and Ruster, 2003; Iweka and Adebayo, 2015; Keivani and Werna, 2001; Khalifa, 2015; Matamanda, 2019). All these factors create a complex situation that is difficult to understand and tackle (Gulyani and Bassett, 2007; Iweka and Adebayo, 2015). The complex and multi-dimensional nature of urban settlements upgrading are observed also in the Global North, for example in the United Kingdom and the United States of America (Lewis, 2017; Fullilove, 2016). Both these studies have particularly highlighted failures to deal with aspects related to maintaining and reconstructing social ties and economic activities - where the consequences were psychological trauma and an exacerbation of generational poverty.

In this study, we focus the attention on livelihoods reconstruction - a dimension that is largely overlooked. As many upgrading interventions involve broad changes in social, material, economic,

\footnotetext{
${ }^{1}$ We will denote the targeted settlement dwellers as 'beneficiaries' because this is a very widely used term in the actual projects. However, ironically many of these people do not reap any benefits and often even end up in worse livelihoods conditions than before.
} 
temporal, and spatial conditions at the domestic level, the interventions disrupt daily routines and practices that in turn affects how livelihood resources are mobilized. The disruptions are significant especially when relocation of people is imperative during settlements upgrading (Iweka and Adebayo, 2015). People have to reconstruct entire activities and practices related to meeting their livelihoods requirements after a relocation. The current state of literature on settlements upgrading suggests that actual impacts of disruptions on the beneficiaries are still under-studied and under-conceptualized (Rigon, 2014; De Geest, 2016; Gulyani and Bassett, 2007; Tissington, 2012; Napier, 2007; Smith and Brown, 2019). This research gap is significant for African cities where, in a more general sense, fewer studies have been conducted in comparison to Asian and Latin American cities (Gulyani and Bassett, 2007: 487).

Considerations to how beneficiaries meet their needs and preferences in settlements upgrading have not been entirely ignored. Researchers and project implementers have explored sustainable livelihoods and participation concepts to tackle this concern. We suggest, however, that current application of these concepts still has significant limitations. While sustainable livelihoods recognises a range of assets that facilitate livelihoods (physical; financial; human; social and natural), the approach has not been effective in capturing how individuals secure livelihoods under precarious circumstances (Smith and Brown, 2019; Appendini and Zoomers, 2001; Cherunya et al., 2020). Therefore, our study builds on the 'time-space' dimension of daily life and contributes to better understanding about how people's needs are met and managed in contexts where their livelihood assets are continuously unreliable. Additionally, we challenge the conventional application of participatory approaches, which often facilitates meeting the needs of project implementers over those of the beneficiaries. We suggest that participatory approaches need to be implemented in such a way that they maintain a stronger beneficiary lens. This way, the approach can be more meaningful in grasping and addressing the daily challenges that beneficiaries have to cope with during actual upgrading and even in the postimplementation stage.

To elaborate on these points, we mobilize a recent insight that builds on practice theory - the Oscillating Domestic Space (ODS) - which conceptualizes processes of reconfiguring livelihoods (Cherunya et al., 2020). Practice-theoretical approaches aim at understanding how actors organize their everyday lives and how this impacts the uptake of new technologies, practices and services (Cherunya et al., 2020; Hargreaves et al., 2013; Shove et al., 2012). The ODS concept fundamentally bases its analysis on time-space characteristics of daily life and enables a mapping of the dynamic areas in which livelihoods activities are organized. In these terms, introduction of new social and material arrangements during settlements upgrading can be equated to a disruption of the domestic space, which cannot be compensated by improving only the material infrastructures. By focusing on the 
processes of domestic space reconstruction during actual upgrading interventions, the agency of dwellers in a broader socio-technical systems change is considered (Shove and Walker, 2007; Hargreaves et al., 2013) - compared to engaging them as mere providers of improved planning parameters through consultations.

We conduct the analysis in two steps. First, we reconstruct how relocated beneficiaries have to reconfigure their domestic spaces to recreate access to opportunities under uncertain and constantly changing conditions and capabilities. In a second step, we analyse how disruptions from relocations jeopardize project success, through manifold negative impacts on legitimacy and on physical state of infrastructures and material artefacts.

We test our framework with the Kenyan Slum Upgrading Initiative (Kensup), an integrated government-led initiative in Nairobi, Kenya. The project started more than ten years ago and is still ongoing after the completion of its first phase. Despite largely relying on a participatory framework, livelihoods needs were inadequately met in the project and most beneficiaries were relegated deeper into poverty conditions. Our analysis draws on interviews with beneficiaries and employees of Kensup, and with sector professionals and experts.

Following this introduction, we have structured the paper as follows. In Section 2, we review approaches to settlement upgrading and how livelihoods reconstruction has been analysed so far. We then introduce the practice perspective and elaborate the ODS concept. Furthermore, Section 2 introduces an approach to analyse feedbacks from livelihood construction activities on legitimacy and on material aspects in settlement upgrading. Section 3 explains the methodology, which entailed analysing a set of primary qualitative data. Section 4 provides empirical evidence on how failures in livelihoods reconstruction in the case of Kensup impacted the upgrading process. In section 5, we conclude by discussing the usefulness of our analytical approach.

\section{Conceptual approaches}

\subsection{Meeting beneficiary needs in informal settlements upgrading}

There are two main forms of informal settlements upgrading that have gained traction: (a) in-situ upgrading and (b) upgrading involving the relocation of residents. In-situ upgrading is based on an incremental upgrading without displacement or relocation. Empirical evidence from numerous upgrading initiatives has shown support for in-situ upgrading citing that, if correctly implemented correctly: disturbances to the livelihoods of the beneficiaries are minimized, relocation and reallocation expenses are avoided, and social ties among community members are maintained (Huchzermeyer, 2009; Keivani and Werna, 2001; Fullilove, 2016; Lewis, 2017). Nonetheless, in-situ 
approaches are often incremental and may not be the best option in all situations - for example where large infrastructures like sewers and roads have to be constructed (Huchzermeyer, 2009; Gulyani and Bassett, 2007). In upgrading with relocations, settlement dwellers are temporarily relocated to an offsite settlement (decanting site) before they return to the area of their previous homes - where new apartments with improved basic service facilities have been constructed. ${ }^{2}$

Contemporary upgrading initiatives, both in-situ and with relocations, have largely failed to produce the desired improvements to the beneficiaries. They are depicted as being expensive undertakings with at best only limited positive impacts for the urban poor (Turley et al., 2013; Keivani and Werna, 2001; Khalifa, 2015). Problems of politicization, corruption, coordination and lack of participation, complexity of evaluation techniques, weak financial mechanisms, weak performance of formal institutions, tenure rights, and social conflicts have been discussed in various literatures to impede successful upgrading, especially when initiatives are government led (see Abbott et al. (2001), Gulyani and Bassett (2007), Imparato and Ruster (2003), Iweka and Adebayo (2015), Khalifa (2015), and Matamanda (2019)). The range of planning, management, and governance limitations often change the course of an upgrading initiative resulting in situations where the upgraded areas become gentrified. Low-income communities are unable to cope with participatory requirements, financing requirements and the new lifestyles required to adapt to their new homes (Ascensão, 2018; Cadavid, 2010). They are sometimes cheated out of their benefits due to corruption. The beneficiaries may eventually resort to giving up ownership and relocating to other informal settlements to start over. In their place, middle-income communities and socio-politically powerful individuals move into the upgraded areas (Cadavid, 2010; Morrison, 2017). With these challenges, failures to meet the needs of beneficiaries in informal settlements upgrading could push poor people further into poverty (Gulyani and Bassett, 2007; Cadavid, 2010; Gomersall, 2018; Moser, 1998; Fullilove, 2016). In order to avoid such consequences, a deep understanding about how informal settlement dwellers manage their livelihoods and practical approaches that take care of livelihood reconstruction needs are required.

In research, it is suggested that current studies lack an understanding about how upgrading processes influence livelihoods activities and daily practices of beneficiaries. The conventionally studied 'conditions for successful upgrading' portray a provider perspective, for example focusing on conflicts management so as to facilitate timely execution of project activities. Fewer studies have taken a critical look at the lived experiences of beneficiaries and how they meet their livelihoods needs during the upgrading process (Rigon, 2014; De Geest, 2016; Tissington, 2012; Napier, 2007). Tissington (2012: 3)

\footnotetext{
2 Upgrading with relocation can be differentiated from resettlement which entails permanent relocation of communities. This is, for example, the case when communities have to be moved permanently from a contaminated or a dangerous living environment such as a landfill or an area prone to land or mudslides.
} 
argued that the nexus between informal settlement upgrading, livelihood creation and local economic development has not been explored in South Africa. In the same context, Charlton (2006) suggested that the link between where people live, and where and how they earn an income is weakly understood or conceptualised. Napier (2007) and Mesplé-Somps et al. (2016) have argued that assessments of how settlements upgrading has impacted livelihoods has not been common-practice in general. However, when such assessments are undertaken, many authors explore relationships between the state (or other project implementers) and communities, and very little literature problematizes the community itself (Rigon, 2014: 258). Hence, we conclude that community-level analysis of livelihoods reconstruction processes is insufficient and deserves more attention.

In practice, project implementers utilise participatory approaches to accommodate to the communitylevel circumstances in settlements upgrading. We suggest that participatory processes are often appropriated to enhance effective project planning and they stop short of eliciting and incorporating beneficiaries' real needs, hopes and expectations. The practical approaches to participation tend to overlook the intricate aspects related to reconstruction of livelihoods by beneficiaries. In the literature, participatory approaches are criticized as not being sensitive enough to account for differences of class and gender (Margalit and Kemp, 2019; Williams et al., 2015). The approach has also failed to be operationalized into a participatory local-level poverty reduction intervention (Moser, 1998; MacPherson, 2013). Additionally, Samndong (2018) found, in an analysis of a REDD+ project in Congo, that participation was effected as an instrument for legitimation and to improve the efficiency and effectiveness of project planning. As such, the author refers to this as a 'participation illusion' where participation maintains minimal benefits for the communities concerned. Similar sobering results are reported in participatory policy development processes where it is often challenging to meet equitable representation of poor community members during decision making (Wesselink et al., 2011; Morrison, 2017; Rigon, 2014; MacPherson, 2013). In reference to Sherry Arnstein's (1969) popularized ladder of citizen participation, we suggest that current participatory approaches are essentially limited to encouraging information and consultation. They do not proceed to the steps of providing actual resources and capabilities to enable community members to proactively co-develop the project through all implementation stages.

In our view, the challenge arises because a broader interpretation of participation is often promoted in settlement upgrading interventions. There is often an assumption that community members know what would work for them and that they can foresee their future needs. Project implementers therefore rely on consultation in the planning stages to receive feedback on the beneficiary needs and preferences. We suggest that this approach to participation does not capture the degree of complexity and the range of considerations when settlement dwellers reconstruct their livelihoods. More 
precisely, the complexities and uncertainties that characterise everyday access in informal settlements may even make it impossible for beneficiaries to anticipate how their conditions will look like in the future (Cherunya et al., 2020). As such, complementary concepts, methods and approaches are required that enable more intricate engagements and deeper understanding of the challenges that beneficiaries encounter in the reconstruction of their livelihoods. Following our critiques, we propose an analysis of livelihoods reconstruction processes based on the beneficiary's daily life experiences drawing on insights from practice theory.

\subsection{Analysing livelihoods reconstruction using the ODS concept}

Livelihood opportunities entail the capabilities, assets and activities required as a means of living (Chambers and Conway, 1992; Scoones, 1998). Livelihood as a concept became mainstream in the 1990s when there was a shift of viewpoint in development practice from structurally-oriented towards more actor-oriented approaches (Sakdapolrak, 2014; Appendini and Zoomers, 2001). The central objective of a livelihoods approach is to capture and provide a means of understanding the fundamental dimensions of poverty and tries to sketch out the relationships between the causes and manifestations of poverty (Majale, 2001). The Sustainable Livelihoods Framework (SLF) has been used broadly in informing strategic thinking and discussion and in re-assessing existing interventions and activities (Majale, 2001) in many sectors including infrastructure development, agriculture, energy, water, forestry and sanitation. Most development agencies adopt the Chambers and Conway (1992) definition and the United Kingdom's Department for International Development (DFID) framework (Solesbury, 2003) which specify livelihoods assets as: natural capital (land, water, wildlife, biodiversity, environmental resources), physical capital (water, sanitation, energy, transport, communications, housing and the means and equipment of production), human capital (health, knowledge, skills, information, ability to labour), social capital (relationships of trust, membership of groups, networks, access to wider institutions), and financial capital (regular remittances or pensions, savings, supplies of credit). To the knowledge of the authors, only Minnery et al. (2013), Mitra et al. (2017), and De Geest (2016) have used the livelihoods concept as a systematic tool in analysing existing informal settlement upgrading interventions and activities. Despite wide application, the SLF has also received criticism, including: lacking integration into established fields that analyse social and economic change processes (Geiser et al., 2011; Small, 2007), a tendency to downplay power relations in access modalities by focusing overly on capital resources and activities (De Haan and Zoomers, 2005), and lack of contextual considerations (De Haan and Zoomers, 2005; Meikle et al., 2001; Moser, 1998). Meikle et al. (2001) and Moser (1998) have argued for a need to further conceptualize the livelihoods concept for its application in tackling urban-related poverty challenges where profiles of households assets and activities differ significantly among community members. 
In order to tackle these criticisms, increasing numbers of researchers are proposing further specification of sustainable livelihoods based on insights from practice theory (see e.g. De Haan and Zoomers (2005), Sakdapolrak (2014), and Thieme (2008)). Practice theory is an established field in social sciences that is used to understand social practices and how they influence societal change processes (Shove et al., 2012; Cherunya et al., 2020; Hargreaves et al., 2013). In this study, we build our analysis of livelihoods on the concept of Oscillating Domestic Spaces (ODS), which was formulated by Cherunya et al. (2020) to capture the space-time structure of practices in highly precarious and uncertain contexts - like informal settlements. They suggest that people have to continuously rearrange daily activities in time and space. Additionally, the people use a multiplicity of alternative options and partial solutions as a means to meet their needs in the quickly changing and precarious circumstances. By this, the concept not only analyses livelihood opportunities but more significantly how the constantly changing contextual factors affect livelihoods practices.

The ODS concept defines the domestic space as the social and material expanse related to making a home which is manifested in daily interactions with other people and the material world in time and space (Cherunya et al., 2020). Oscillations are a combination of the regular and the erratic fluctuations in external conditions and personal capacities that enable or disable the performance of specific practices (Shove et al., 2012; Cherunya et al., 2020). Conditions of oscillations are challenging because they make it hard to predict how, where and when a domestic activity can be undertaken. For example, for an individual to access a pay-per-use toilet in an informal settlement, irregular income patterns (i.e. capacity) would imply that he or she may lack money to pay for access in unpredictable ways. The personal capacity challenge is combined with infrastructural precarity (materialities) whereby, for example, communal toilets are not always open and available as they are affected by irregular water supplies. There exist also socio-cultural precarities (meanings) that influence how and where services can or cannot be accessed; as is the situation with women being unable to use communal toilets at night because of safety concerns. Such uncertainties push settlement dwellers to constantly rearrange their service access activities in time and space drawing on a multiplicity of alternative strategies. Based on insights from practice theory, Cherunya et al. (2020) have specified four elements or preconditions for practices: materials, meanings, capacities and time-space. Essentially, a practice entails specific bundling of elements which become routinized over time (Shove et al., 2012). In the context of informal settlements, a specific practice - such as toileting - may require diverse sets of practice elements with a variety of possible bundling of the elements: for example, materialities (public toilet, neighbours toilets), meanings (choosing one option over others), capacities (availability of money, possibility to access on credit, accessibility of roads), time-space (day, night, at home, in the neighbourhood). Central to the ODS concept is the idea of everyday uncertainties, competing 
obligations and a need for prioritizing, which pushes people to diversify access options and sometime even fail to conform with socio-cultural expectations in order to meet their needs (Cherunya et al., 2020).

The ODS concept is complementary to what has already been developed by sustainable livelihoods scholars. The ODS, for example, is in line with the understanding of livelihoods practices by Long (1997: 11) who suggests that livelihood best expresses the idea of individuals and groups striving to make a living, attempting to meet their various consumption and economic necessities, coping with uncertainties, responding to new opportunities, and choosing between different value positions. Practice preconditions in ODS are complementary to some of the livelihoods assets defined in SLF. The 'materialities' and 'capacities' are captured within the natural, physical, human, social and financial assets of SLF. De Haan and Zoomers (2005) suggested the extension of livelihoods concept to emphasize socio-cultural meanings and local power that has been overlooked in the original conceptualization. This precondition is specified in the ODS concept as 'meanings'. An additional strength of the ODS concept is its ability to analyse the 'time-space' dimension of livelihood activities - which makes it possible to analyse conditions of precarities. The ODS concept was developed originally based on an empirical case where socio-technical innovations (sanitation technologies) are introduced (Cherunya et al., 2020). As such, ODS has a conceptual strength for systematic analysis of existing projects. In informal settlements upgrading, the beneficiaries will be uprooted from their former homes where they had established their livelihoods practices and are introduced into new social, material and spatial contexts. When relocated, the complex livelihoods practices have to be reconstructed. Depending on social and material resources that prevail in the new places, livelihoods reconstruction processes may result in various forms of disconnections and disruptions in how practices are carried out in domestic spaces. Figure 1 presents a visualization of how domestic spaces are transformed during relocation in informal settlement upgrading. The comparative visualization highlights the kinds of disruptions that could occur. 


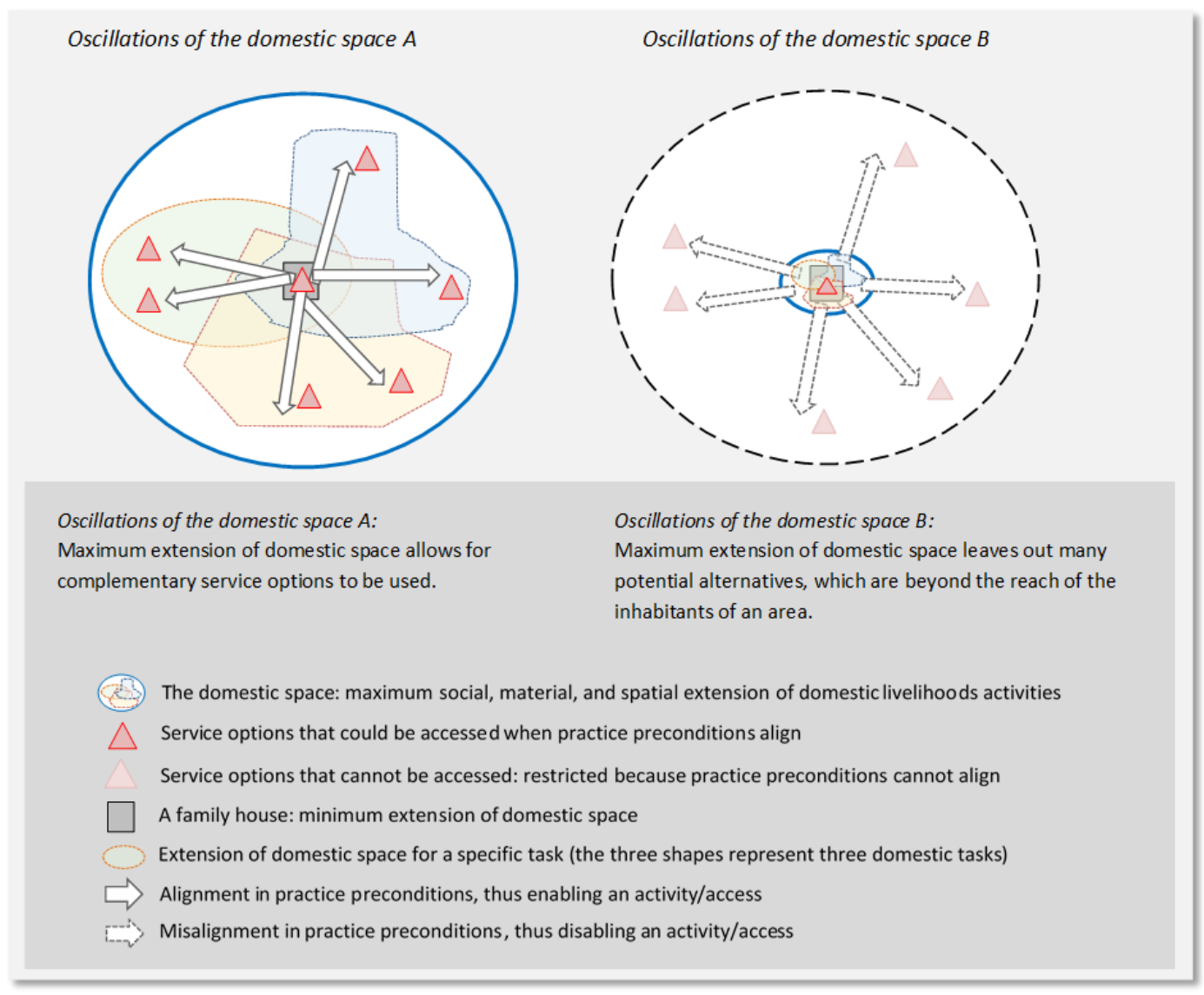

The first diagram (oscillations of the domestic space A) represents the expanse of the domestic space in an informal settlement, which goes beyond a family house. Cherunya et al. (2020) explain how meeting daily needs in informal settlements entails continuous interactions with diverse individuals (e.g. friends, neighbours, service providers) and diverse service options for similar domestic tasks. Users are required to navigate opportunities and negotiate access daily. To cope with very difficult circumstances, they sometimes are even forced to contradict social rules in order to gain access to basic domestic requirements. This way, they are able to meet daily needs despite precarity in practice preconditions such as incomes, reliability of services, safety and security conditions, weather changes etc. These dynamic socio-material interactions in the domestic space are critical to meeting livelihoods needs in informal settlements (Cherunya et al., 2020)

The second diagram in Figure 1 (oscillations of the domestic space B) represents a situation where the domestic space in an informal settlement becomes shrunken, for example when people are relocated to a conventional middle-class gated community. The diagram illustrates that a wide range of alternative service points, service providers, and additionally friends and neighbours are disconnected from the domestic space. While the housing condition is improved, often the beneficiaries still engage in similar socio-economic activities and problems with service reliability may persist. Their coping 
strategy of rearranging practices in time and space and the use of multiplicity of alternative options and partial solutions cannot be actualized. With the ODS concept, we can ask the following questions in the implementation of a project: (a) How can the domestic space be mapped? (b) Where, when and in how many ways are livelihoods activities carried out in domestic spaces? (c) What precarities in practice preconditions exist in the local environment and with individuals? (d) How do people respond to the precarities in order to meet their livelihood needs? Answering these questions will enable identification of the specific aspects necessary to support livelihoods reconstruction in upgrading projects.

The drastic transformation in domestic spaces that happens in a relocation, as explicated in Figure 1, shows that improving livelihoods requires a multi-dimensional reconstruction beyond having new sanitized houses. This factor is critical to successful informal settlement upgrading and should inform strategic thinking and discussions. In order to explicate the significance of taking care of livelihoods reconstruction needs, we analyse in this study the implications of livelihood outcomes on an existing intervention. We analyse the impact of disturbances on the domestic spaces in a relocation on two primary success conditions of upgrading projects: the legitimacy of the upgrading process and the physical state of infrastructures and artefacts.

Creating and maintaining legitimacy of a settlement upgrading project is essential in creating support, or a buy-in, by the targeted beneficiaries and this is achieved when the beneficiaries are confident that their livelihoods needs will be taken care of at the end of the process. A buy-in emerges from a successful participatory approach: including, among other activities, inclusion of informal forms of governance and local leaderships, transparency in project implementation, effective decision making platforms to reach agreeable forms of financial contributions by beneficiaries, gender inclusion, creation of information sharing and complaint platforms, and developing shared visions, objectives and expectations between project initiators and the beneficiaries (Rigon, 2014). When beneficiaries are not able to meet their livelihoods needs or feel their livelihoods are threatened, they may react by refusing to support an initiative further (Mitra et al., 2017; Rigon, 2014). In addition, challenges in the reconstruction of livelihoods may jeopardize the sustainability of the new material improvements. $A$ reconstruction of the domestic spaces has a strong material dimension. People will attempt to restructure physical environments in the process of livelihoods reconstruction as a coping strategy when their livelihoods are not adequately met. This may hamper the material integrity of improved infrastructures. As such, we suggest that the three dimensions - livelihoods reconstruction, legitimacy and physical infrastructures - have interlinkages and feedbacks, which influence the overall success of a settlement upgrading initiative. 


\section{Methodology}

We test our framework using the case of the Kenyan Slum Upgrading Initiative (Kensup) in Kibera, the largest informal settlement in Nairobi, Kenya, which has a population of 200,000 inhabitants (Meredith and MacDonald, 2017). Kensup was launched in 2002 as the first state-led slum upgrading initiative to receive national budgetary allocation. Kensup involved temporarily relocating the settlement dwellers of Soweto East-A neighbourhood to an offsite settlement known as the decanting site, giving space to redevelop the settlement. This would be followed by a reallocation into the new and improved modern housing. Relocation was necessitated by the need to install large sewerage infrastructures and the decision to economise on space by constructing high-rise buildings (UN-Habitat, 2007).

The Kensup initiative in Soweto East-A is well suited to demonstrate the value of our analytical approach because life in the decanting site provided entirely new socio-spatial conditions for livelihoods to be reconstructed. The initiative adopted an inclusive participatory approach that was aimed at improving the livelihoods of people by guaranteeing programme ownership and sustainability (UN-Habitat, 2007: 13; KNCHR, 2018).

This study is based on two sets of data: the first comprised 50 quantitative interviews from a preliminary study of Kensup in May 2017. The preliminary study informed a second round of qualitative data collection in April 2018, which specifically targeted the questions related to livelihoods reconstruction. The first author conducted 24 qualitative interviews with Kensup officials, a sector expert representing an NGO, people living in the decanting site, beneficiaries living in their new upgraded apartments, and people who moved back into informal settlements (Table 1). This second set of data is referenced in this paper.

Table 1: Interview respondents

\begin{tabular}{ll}
\hline Interview respondents & Number \\
\hline 1. (former) Kensup employees & 5 \\
\hline 2. Sector expert & 1 \\
\hline 3. Decanting site inhabitant & 8 \\
\hline 4. Recipients upgraded units & 7 \\
\hline 5. Displaced persons (to other informal settlements) & 3 \\
\hline Total & $\mathbf{2 4}$ \\
\hline
\end{tabular}

Semi-structured interviews were the main form of inquiry. For the beneficiaries, the interview guideline contained general thematic categorization of questions to allow participants to tell their own stories on their own terms. The interviews were complemented with observations of places where domestic activities are carried out. The recorded interviews were translated from the local language 
Kiswahili into English then transcribed and coded using MaxQDA12. The set of codes included domestic activities, response strategies to precarities, the impacts on legitimacy, and the impacts on physical infrastructures.

In the following sections, we will highlight the experiences of the beneficiaries when they lived in Soweto East-A before 2009 (the informal site) and when they lived at the temporary decanting site. Comparing daily activities in the two contexts is beneficial in highlighting livelihood reconstruction processes that dwellers had to enact at the decanting site. Between 2005 and 2009, participatory initiatives were undertaken at Soweto East-A where 6,377 households lived (KNCHR, 2018: 29). About 1200 of the households were relocated in 2009 to a decanting site about 4 kilometres away (KNCHR, 2018: 33). Figure 2 presents a map of Kibera informal settlement showing the locations of Soweto EastA and the decanting site.

Figure 2: Map of Kibera informal settlement in Nairobi showing the locations of Soweto East-A and the decanting site. Source: adapted from Google Maps

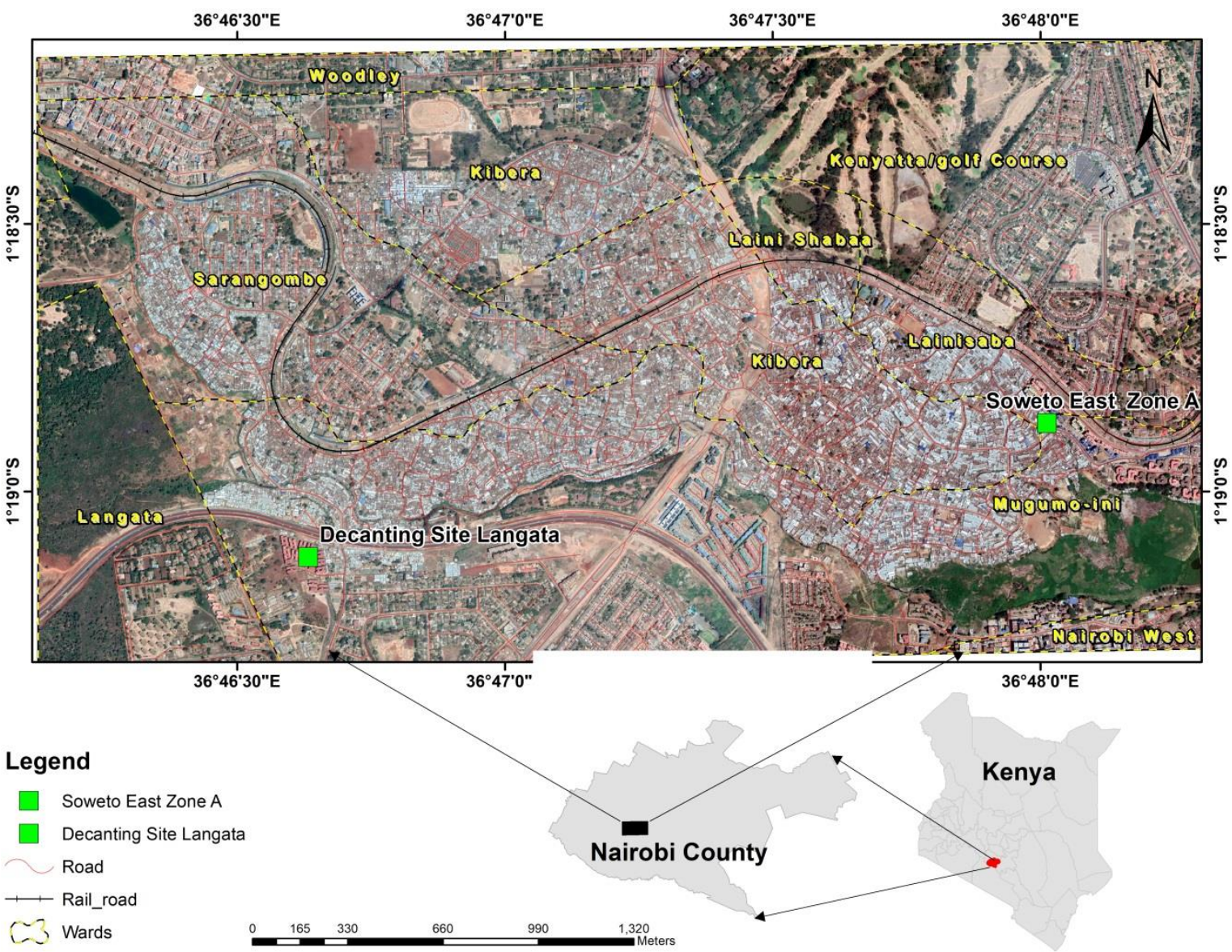

We analyse the livelihood reconstruction experiences of the resettled inhabitants between 2009 and 2016 when they lived in the decanting site. Here we highlight experiences with the new housing facilities as well as the daily livelihoods activities. In a second step, we analyse the interlinkages 
between livelihoods reconstruction, legitimacy and the state of the physical amenities at the decanting site.

\section{The implications of livelihoods reconstruction on Kensup}

We present the findings of this study in three steps. First, we elaborate on the actual participation efforts that were made by the program managers of Kensup. We then reconstruct the major challenges that the dwellers confronted when trying to reconstruct their domestic spaces after relocation. Finally, we explain how the problems encountered led to an erosion of legitimacy and of the physical integrity of the project.

\subsection{Conventional participation approach to building legitimacy with beneficiaries}

At the beginning of the upgrading process in 2005, Kensup officials conducted physical mapping, enumeration of beneficiaries, and a socio-economic survey of the informal site, Soweto East-A. The survey inquired about incomes, expenditures, household sizes, and assets such as numbers and sizes of houses and businesses owned. The survey additionally inquired about the costs the beneficiaries were willing to incur for rent at the decanting site (Kensup employees $1 \& 3$ ). The survey culminated in a database of 6,377 households identified as the beneficiaries.

For a participatory process, an information sharing and deliberative platform, locally known as barazas, were set up. The barazas were particularly essential because of a severe lack of trust by the local inhabitants towards the government - who was the principal project implementer. According to the locals, improved houses from a previous upgrading initiative were arbitrarily given to unknown people and failed to benefit the genuine low-income families. The beneficiaries therefore perceived such upgrading processes as an indirect displacement (Recipient $3 \& 7$, upgraded unit).

"The beneficiaries feared that once the project was completed, the improved housing units would be given to the rich people and people of Kibera would lose - as was experienced in the nearby high-rise estate project (...) they lied to Kibera people previously" - Recipient 3, upgraded unit

In addition to the barazas, individuals were selected among the beneficiaries to be part of the Settlement Executive Committee and represent the views and ideas of different social, cultural and economic groups. Considering the disruptive and complex nature of the project, these two deliberative platforms created a 'buy-in' of the beneficiaries into the project (Kensup employee 1). One outcome of the deliberations, which helped in creating trust and legitimizing the project, was provision of special identity cards to beneficiaries to be a physical symbol for entitlement to an upgraded house (Kensup employee 3). 
Despite these positive outcomes, other issues could not be tackled successfully in the platforms. One of them was where the decanting site was to be located. The beneficiaries disagreed with a proposed location $30 \mathrm{~km}$ away fearing they may not be able to easily access basic amenities like schools and hospitals as it would be too far from the city. They also feared they could be easily abandoned and forgotten if the process failed to be successful (Recipient 2, upgraded unit). Kensup was adamant citing cost implications and lacking feasible alternatives nearby. Eventually Kensup managed to acquire a closer alternative $4 \mathrm{~km}$ from the informal site after receiving external pressures from influential politicians (Recipients 1, 3 \& 4, upgraded units). A 'one upgraded apartment unit per family' principle was another challenging deliberation in the barazas. It faced disapproval by some settlement dwellers who claimed larger compensation owing to larger assets they owned at the informal site. The dissatisfied community members considered legal solutions, which became a lengthy process contributing to unforeseen delays of about two years in the project (Kensup employee 3).

Before the identified beneficiaries were moved to the decanting site, pre-visits had been organized so that the resettled get acquainted with the location and the new amenities. Kensup hired sociologists to sensitize and educate on behaviour changes.

"We did not want them to have culture shock. We prepared them thoroughly, we trained them on how to behave when they move to the decanting site, how to socialize living with new neighbours, also living in the houses that are very different to what they had before" - Kensup employee 1

The sensitization activities were an important intervention by Kensup in supporting livelihoods reconstruction: to ensure daily practices in the decanting site do not leave negative impacts on the physical integrity of the new housing amenities.

Additionally, beneficiaries were trained on business acumen and effective saving plans during this stage of the project. Kensup required that beneficiaries engage in a saving plan in order to raise a $10 \%$ initial payment towards ownership of the new upgraded apartments that would be constructed in the informal site. The remaining cost would be paid as a long-term mortgage plan. The trainings provided were to support the saving plans towards ownership but also to enable the beneficiaries to rebuild their livelihoods activities once relocated (Kensup employee 2).

In summary, the onset of the initiative focussed mainly on building legitimacy and creating a buy-in by community members into Kensup. Some support for livelihoods reconstruction was provided in this stage of the project which mainly focused on the provision of soft skills through information and trainings. 


\subsection{Challenges of reconstructing new domestic spaces in the decanting site}

Construction of the decanting site was completed in 2009 and 1,200 willing households were relocated immediately. The remaining, over 5,000 families, were required to self-organize for alternative housing as the decanting site lacked capacity to host all the households. The decanting site contained modern facilities similar to the planned upgraded apartments that would be constructed in Soweto East-A.

The ODS perspective informs that informal settlement dwellers constantly must rearrange their practices in time and space in their quickly changing and precarious local contexts. They often rely on a multiplicity of alternative options and partial solutions to meet their needs. A relocation implies fundamental changes in the social, cultural, material, spatial and economic conditions that requiring enormous efforts on the side of the dwellers to reconstruct new domestic spaces. As such, the decanting site represented a situation where the domestic space of the beneficiaries was suddenly shrunken and was socially, culturally, materially, spatially, and economically different from the informal site. In particular, the neighbourhood was gated, service access was limited to one existing option, and several previous practices from the informal site were restricted. The project implementers adopted a middle-income household vision in their planning approach where the domestic space was assumed to coincide with the physical boundaries of an apartment. In the following, we present the basic service infrastructure conditions (materialities), socio-cultural dispositions (meanings) and the personal and effective capacities of settlement dwellers (capacities) to cope with livelihoods reconstruction process in this new context.

A first precondition for reconstructing livelihoods relates to the materialities - that is in terms of physical infrastructures and amenities within the new spatial context. For the new inhabitants of the decanting site, what was expected of them did not align with the infrastructural conditions in terms of services reliabilities. While the new domestic amenities like the in-house taps and toilet facilities provided modernized options, the water supply remained intermittent and unreliable. The gated status of the decanting site and restriction of business activities within meant that the dependence of a diverse set of alternatives that are present in the informal site could not be re-enacted. For example, water vendors were restricted from extending their services into the decanting site. The in-home access points became the only dependable option despite its frequent unavailability. People, therefore, were forced to go a long way outside the decanting site to find water for domestic use and it became a physically exhausting task. The households living in the higher storeys of the apartments suffered more as they often did not get water at all due to insufficient water pressure and they had to carry large water containers up the stairs.

In Zone-A (informal site) at least there were many water vendors so there was always a place to source for water. Here (decanting site) we struggle a lot. (...) we have to leave the 
neighbourhood and go outside the gated area into the neighbouring settlement to find water. (...) we have to carry a lot of water up the stairs - Decanting site inhabitant 7

A negative consequence from this on the functionality of the modern toilets was that people extremely limited the amounts of water used for flushing, or they upcycled unfiltered kitchen wastewater for flushing thus leading to serious sewer blockages and overflows (Kensup employee 3).

The second precondition for reconstructing livelihoods relates to meanings and socio-cultural dispositions. Adjusting to life in the decanting site triggered social-cultural conflicts among the inhabitants. Domestic chores were restricted to only being done inside the apartments - thus deviating greatly from how the households had previously managed daily activities by utilizing spaces beyond the house ${ }^{3}$. In addition, two families were required to share domestic facilities like the kitchen space, bathroom and toilet. Only 632 apartments could be provided at the decanting site to host 1200 families; therefore an apartment unit had to be shared between two families. Sharing of apartments and the lack of possibility to extend domestic activities outside of the house resulted in congestion which triggered social conflicts (Kensup employee $1 \& 5$ ); Recipients 2, 4 \& 7, upgraded units). Many households chose to live with the difficult living conditions perceiving it as a temporary perseverance for an eventual long-term benefit (Kensup employee 1). Significantly, they considered being present at the decanting site an assurance to maintaining their entitlement as a beneficiary.

"I preferred living in the decanting site because I had a better chance to receive information about the progress of the initiative and this way act accordingly and avoid the risk of being excluded" - Recipient 3, upgraded units

The situation became continuously more complex because of delays in the entire project. As of 2018 when data used in this study was collected, the people in the decanting site had been there for nine years instead of the originally planned period of two years. Family sizes expanded, thus exacerbating the congestion problems and bringing about dilemmas about whether families should relocate to bigger housing outside the decanting site or stay in order to secure their entitlements (Decanting site inhabitant 6). In the context of families having to deal with growing kids, one coping strategy of families in the informal site was to collectively rent a housing unit nearby which would host some of the young males from various families (Decanting site inhabitant 1; Sector expert 1). Essentially this housing unit would be used for sleeping but the occupants would take care of their domestic needs within their individual family-homes. The arrangement would relieve household members from pressures related to use and sharing of domestic spaces between older and younger family members. This coping

\footnotetext{
${ }^{3}$ In their recent study, Cherunya et al. (2020) have provided a detailed account of the mapping of domestic spaces beyond the house in Nairobi's informal settlements.
} 
strategy could not be reconstructed at the decanting site because all the surrounding apartments had been occupied and taking an extra housing unit beyond the domestic space (i.e. outside the gated neighbourhood) would be inconvenient for activities like having joint meals. It would also bring concerns related to security and safety of the young boys.

The third precondition to reconstruct livelihoods is related to the capacities to meet daily needs. These are related to managing intermittent incomes and leveraging community networks. Similar with the informal site, conditions of economic precarity were still present at the decanting site. A majority of the beneficiaries were dependent on informal and small-scale employments implying that income flows are intermittent. In addition to the provided training on business management and savings at the onset of the project, Kensup provided a few beneficiaries with spaces where they could open shops that would serve the local population. The intervention was beneficial but had minimal outcome in terms of stabilising the incomes of most beneficiaries. In fact, the relocation meant for many having to quit their previous jobs and to try and set up new ones. No other economic empowerment support beyond this was provided for the beneficiaries. It was reported that, for Kensup, other project activities became time and resource constraining so that aspects related to building the economic capacities of beneficiaries was not prioritised (Kensup employee 1). However, the setting up of home-based enterprises was highly controlled in the decanting site and was prohibited for the majority. In any case, home-based enterprises would not be successful in the decanting site because access by outsiders, who could increase the customer base, was restricted. The loss of economic activities and inability to re-establish remains the biggest challenge to date. Figure 3 symbolizes the desperation of an elderly interview respondent. She put up her small business in front of one of the buildings despite not having any produce to sell from her empty cans and despite of having virtually no passers-by customers within the decanting site. 


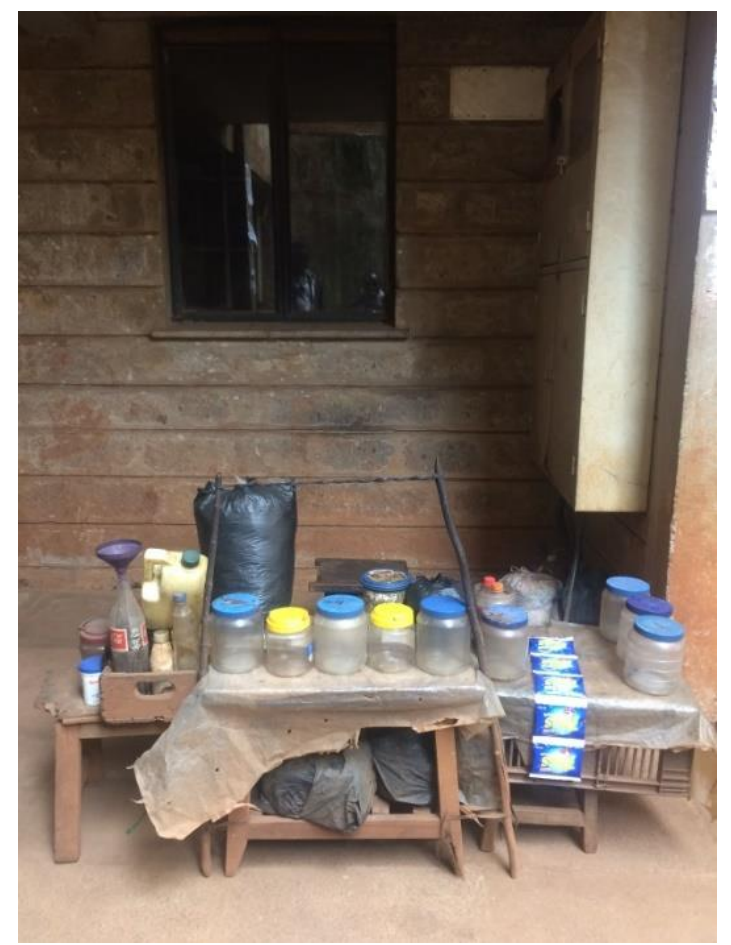

In relation to rent affordability, Kensup had set the charge at the decanting site to be similar to what dwellers paid in the informal site (Kensup employees $1 \& 3$ ). Despite this, many of the respondents informed that they struggled to pay the needed amounts as the economic situation had been made worse. Additionally, the payment for rent and the new services (i.e. payments for water, waste management) at the decanting site required regularized transfer of funds thus representing new economic challenges. Payments were flexibly organized at pay-per-use, daily, weekly or monthly charges in the informal site. However, the decanting site demanded formal and structured monthly payments which, became incompatible with the intermittent incomes (Kensup employee 5). The residents at the decanting site therefore struggled to meet their financial duties. The rent charges might have remained low, but the payment modalities were incompatible and thus affecting tenants' ability to meet the expenses.

It is also important to note that the capacities of informal settlement dwellers largely draw on social connections and networks. These were discontinued due to the relocation and members having to find new homes far from each other. We give the example of local savings and loan groups, locally known as chama, of which many people engage in them to support their saving plans. Engaging in the selfhelp groups assists members to commit more to the shared saving plans in comparison to individual plans which would often be disrupted by many competing livelihoods needs (Recipients $1 \& 6$, upgraded units). The new social context and various social frustrations at the decanting site challenged 
the possibilities of many beneficiaries from setting up new chamas and using them as a livelihood strategy.

To summarize, we can say that the spatial relocation and the new physical conditions at the decanting site distorted the fundamental strategies necessary to cope with the ODS. Superiority of the housing and basic amenities did not automatically make daily practices and livelihoods activities simple and manageable. In fact, it resulted in very difficult circumstances for the beneficiaries as they tried to reconstruct infrastructural and livelihoods related practices.

\subsection{Broader implications on the success of Kensup}

The struggle to reconstruct new domestic spaces that would enable the dwellers to meet their needs led to a whole series of ripple effects. More specifically, it resulted in a progressive deterioration of physical amenities and reduced trust towards the whole Kensup project. Many of the relocated settlement dwellers remain stranded in the decanting site, while others gave up their entitlements and moved back into informal settlements. These broader implications are analysed by looking at the interlinkages and feedbacks between livelihoods reconstruction, legitimacy and physical infrastructures (Figure 4). The letters ' $a$ ' - ' $f$ ' represent the feedback effects among the dimensions and the letters ' $g$ ' represent the overall implications from negative or positive feedbacks. This implies that physical improvement of settlements alone may not lead to overall improvement if the link between livelihoods reconstruction and other success factors are not considered.

Figure 4: Interlinkages between the conditions for success in settlement upgrading

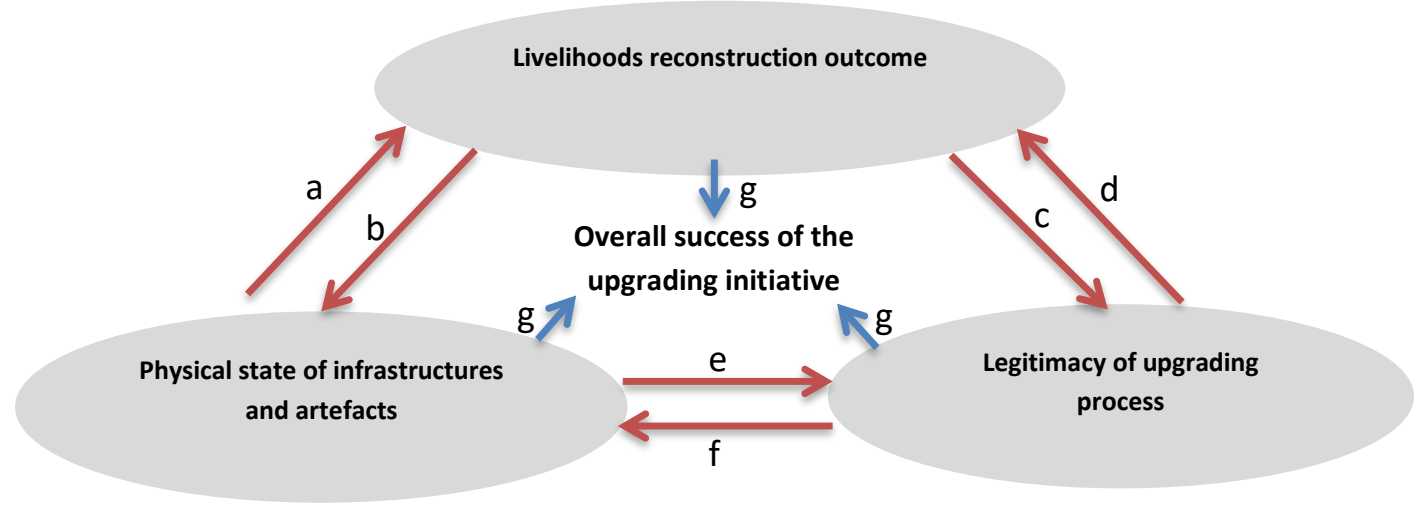

Our empirical findings suggest that Kensup made significant efforts in the pre-relocation phase to capture the needs and priorities of the beneficiaries through surveys and participatory deliberations. These initial efforts seem to have been useful in developing legitimacy and contributing towards a 'buy-in' by concerned settlement dwellers. However, we see that the approaches were not able to capture deeper aspects related to reconstructing livelihoods, as interview respondents cited: 
"We anticipated such challenges, but we really did not expect them to be this difficult and complex to tackle" - Kensup employee 1

"We were not ready at all for the new developments at the decanting site, we really learnt a lot from how things developed there" - Kensup employee 3

Few community meetings were held and no surveys were conducted at the decanting site that targeted a better understanding of livelihoods reconstruction (Kensup Employee 4; Decanting site inhabitant 2). This is indicative of a lack of understanding and consideration to the reality of oscillating domestic spaces and the associated portfolio of service and livelihoods options. As a corrective measure, dwellers started to contravene the original rules and regulations set up by the project managers, for example by looking for new water provision arrangements from outside the decanting site. These new water sources grew organically at the fringes of the neighbourhood to provide alternative supply. Entrepreneurs from the outside would illegally insert a hosepipe through the damaged perimeter fence of the decanting site to supply domestic water at a fee (Figure 4, arrow 'b'). This interlinkage between livelihoods reconstruction and service infrastructure illustrate the limitations of attempts to formalize provision when users are still persistently faced with precarities in terms of consistent access to the service. Users find it pragmatic to respond to these difficulties by diversifying their access portfolios, even to the extent of including options that might be unsafe and unhygienic.

Another example that proves the negative impact on the newly built infrastructures is when an inadequate access to water forced many residents to disable the flush toilet systems converting them to 'pour-flush' in order to minimise water use (Kensup employee 3). The implication for the use of very little water to flush was blockage of sewer systems in the entire neighbourhood. The issue was worsened when households continued the old practice of disposing solid materials into toilets without regard to the difference in toilet design compared to the pit latrines they had in the informal site (Kensup employees $1 \& 3$ ). These activities deteriorated the physical state of the sewerage system leaving people to manage domestic activities in highly unhygienic environments. Based on observation during data collection, wastewater was flowing back through the toilet bowls into some households. The negative impacts on physical state of infrastructures and basic amenities created a vicious cycle when the singular infrastructures further deteriorated and thus exacerbating the difficulties to reconstruct livelihoods (Figure 4, arrows ' $b$ ' and ' $a$ '). This led the beneficiaries to further lose hope in the project (Figure 4, arrows ' $c$ ' and 'e').

"The differences between here and Kibera (the informal site) is, here, we have to live with faeces inside our homes" - Decanting site inhabitant 7 
The failure by beneficiaries to reconstruct livelihoods, combined with the inability of Kensup to proactively manage the unexpected challenges of deteriorating or unavailable amenities led to an increasing de-legitimation of the overall process. The resettled dwellers felt cheated and not supported and thereby expressed decreased trust as the project progressed (Figure 4, arrows ' $c$ ' and ' $e$ '). This resulted in a situation where people stopped saving towards eventual ownership of an upgraded house because they could not afford it and they did not trust the project any longer.

"Many people became disoriented (...) we started feeling like this whole process was an indirect eviction" - Recipient 7, upgraded units.

"No, we are not contributing (...) we are just staying here (decanting site) until the day they decide to do whatever they decide to us" - Decanting site inhabitant 5

Many of the relocated families now remain in a situation of hopelessness at the decanting site and are uncertain about how to progress further in improving their lives (Figure 4, arrow ' $d$ '). With the lack of trust, the beneficiaries lost the sense of ownership of the provided amenities and are not interested anymore in taking care of them (Figure 4, arrow ' ${ }^{\prime}$ '). Many do not any longer follow the restrictions surrounding the use of open spaces. They contravene the requirements by: converting balconies to make additional living spaces or into shops, illegally sub-letting their apartments and finding alternative accommodation back in the informal settlements, or forcefully engaging in home-based enterprises even when forbidden (Kensup employee 5; Displaced person 1; Decanting site inhabitant 4). These issues led to increased frictions between the estate management team and the residents. The consequence is a downward spiralling where facilities continue to deteriorate and the resettled families feel neglected even more (vicious cycle, Figure 4 , arrows ' $e$ ' and ' $f$ ').

The negative feedbacks between livelihoods, physical infrastructure and legitimacy may have relegated many dwellers deeper into poverty (Figure 4, arrows ' $\mathrm{g}$ ') because: the livelihoods activities they had established in the informal site became destroyed by the relocation, they were unable to reconstruct new livelihoods opportunities, and now they restrict themselves from moving on and starting over in new locations because they risk losing their possible entitlement to the upgrade. While a majority remained in the decanting site without much prospects, some of the Kensup beneficiaries gave up hope, abandoned the project and relocated to new informal settlements. Three beneficiaries who chose to move back into the informal settlements reported that they were better able to earn decent incomes through home-based enterprises and profited from more convenient access to basic services (Displaced persons 1, 2 \& 3). One of the displaced persons chose to sub-let his apartment space at the decanting site to earn a regular income from it. The respondent judged a regular income to be more important than living in the sanitized environment (Displaced person 1). 


\section{Conclusion}

This study aimed at elaborating the significance of livelihoods reconstruction as a necessary condition for successful informal settlement upgrading. We leveraged the Oscillating Domestic Space (ODS) concept to better specify how informal dwellers manage their livelihood activities. The approach emphasizes the space-time structure of domestic practices in informal settlements, a highly dynamic, resource constrained setting. The informal settlement dwellers must constantly adapt their practices to unforeseen and ever-changing personal capacities, socio-cultural meanings and physical infrastructural conditions. Dwellers must therefore think and act in terms of constantly changing portfolios of service options. When confronted with a relocation, these complex socio-material interlinkages and relationships must be reconstructed and be spatially and temporally embedded in the new context.

The study of Kensup illustrates vividly how the project implementers' rationales were devoid of the ODS considerations and assumed that the new modern living quarters would provide adequate livelihoods assets. The project implementers were guided by a vision of a middle-income housing condition where domestic spaces coincide with the physical boundaries of an apartment. The relocation and the physical boundaries of the decanting site prevented the inhabitants from accessing alternative services and income opportunities. To cope with the disruptions on livelihood activities, the relocated families resolved to highly disruptive practices which resulted in deterioration of physical infrastructures. The beneficiaries additionally lost trust in the upgrading process when their livelihood practices were compromised, and they felt neglected.

Therefore, we conclude that livelihoods reconstruction needs to receive more attention in settlement upgrading in order to result in actual livelihoods improvements. The experiences reported in our study suggest that many of the alleged beneficiaries were left worse off after huge amounts of public and personal resources were invested into the upgrading process. A majority of those in the decanting site are confronted with the challenge of how and where they will have to start rebuilding their livelihoods after nine years of anticipating a new home and eventually being incapable of benefitting. The numbers suggest that only $12 \%$ of the originally profiled beneficiaries were successful in meeting the requirements and eventually moved into the new upgraded apartments in 2016 (KNCHR, 2018). It is therefore understandable that many interviewees perceive the Kensup project as being an indirect form of eviction. A proper assessment of livelihoods reconstruction is even more urgent for the new upgraded apartments as similar challenges to those in the decanting site are likely to be experienced. The lessons are also critical in the planning of the next phases of the Kensup initiative, as Zones B, C and $\mathrm{D}$ of Soweto East are expected to undergo a similar upgrading process. 
Based on these experiences, we may also draw some implications on the management of upgrading projects. The Kensup case shows that participation as conventionally conceived focuses on building legitimacy and acquiring 'buy-in' by designated beneficiaries and fails at adequately capture the needs towards rebuilding livelihoods. Kensup relied exclusively on a socio-economic survey to analyse livelihoods needs and the assessment of needs was limited only to the pre-relocation phase. Thus, they were unable to capture aspects related to coping with daily uncertainties is access and the need for a more diverse portfolio of service options and income streams. More specifically, the Kensup case illustrates that preference elicitation in participatory deliberations is seriously hampered by the inability of both project implementers and beneficiaries to foresee the challenges that are associated with reconstructing livelihoods. The study shows that livelihoods activities would need to be carefully assessed at the beginning of the relocation project and closely monitored all through the implementation phases. Understanding how practices, assets, capabilities and contextual conditions influence livelihoods activities goes beyond merely conducting surveys. A dialogue is required on the degree of complexity of competing needs, obligations, and the range of considerations for users when they make actual choices under uncertainties. In other words, there is need to install higher levels of participation in the terms of Arnstein's ladder (Arnstein, 1969). This entails an adaptive management approach where practical experiences of the actual beneficiaries are used as a basis to reconfigure the upgrading processes - rather than making use of only initial consultation.

More broadly, this study calls for a reflection on upgrading policies in consideration to the risks that beneficiaries may end up in much worse livelihoods conditions compared to where they were in the beginning. The present study suggests that in-situ upgrading - that is without a relocation - may have several advantages because ODSs do not have to be reconstructed in their entirety. However, we argue that disruptions might also occur under in-situ upgrading. This is in line with the findings by Lewis (2017) who showed that an in-situ urban regeneration project in East Manchester resulted in loss of social ties and thus challenging livelihoods reconstruction activities. As such, a consideration of livelihoods reconstruction ought to be key in any form of settlement upgrading.

The work by Lewis (2017) further illustrates that the relevance of the ODS concept reaches beyond the realm of informal settlements in the Global South. Even though a large share of domestic activities (e.g. water and energy access, waste disposal, laundry, etc.), is carried out within the confines of a family house in higher-income neighbourhoods and in OECD countries, other activities extend into the neighbourhoods or even larger areas of a city. Unforeseen and persistent changes in service availability or personal capabilities may also require a more complex management of portfolios of service options. A possible example would be organizing childcare when both parents must commute to work daily. Here oscillations will depend on reliability of commute systems, health status of the children, 
availability of a caretaker for the children, and so on. We would expect to see similar processes operating under such conditions while acknowledging that the complexity is still lower compared to what we observed in informal settlements. Similarly, challenging situations can also emerge under conditions of displacements or resettlement in the context of conflicts, disasters or natural resource exploitations - where social, material, economic, temporal, and spatial changes occur.

Even though we maintain that an ODS perspective has substantial potential to positively impact upgrading success, we have to also acknowledge the limitations of our approach. In the present analysis we focused on the interdependencies between livelihoods reconstruction processes, legitimacy, and the physical integrity of the project. In general, however, many more factors will influence whether an upgrading process will be successful, such as the quality of project management, the reliability of governance structures, power relations, availability of resources, corruption, and so on. However, the present study suggests that the livelihoods dimension remains a core condition for success which can barely be compensated by any other factor and, therefore, needs sufficient scrutiny.

\section{References}

Abbott J, Martinez I and Huchzermeyer M (2001) An Analysis of Informal Settlements and Applicability of Visual Settlement Planning VISP in South Africa. University of Cape Town, Department of Civil Engineering.

Appendini K and Zoomers A (2001) Land and livelihood: what do we know, and what are the issues. Land and sustainable livelihood in Latin America. 23-38.

Arnstein SR (1969) A ladder of citizen participation. Journal of the American Institute of planners 35(4): 216-224.

Ascensão E (2018) 14. Slum gentrification. Handbook of Gentrification Studies. 225.

Cadavid PR (2010) Moving in-Selling Out: the outcomes of slum rehabilitation in Mumbai.

Chambers R and Conway G (1992) Sustainable rural livelihoods: practical concepts for the 21st century. Institute of Development Studies (UK).

Charlton S (2006) Learning from the local: Experiences of informal settlement upgrading in KwazuluNatal. South African Review of Sociology 37(1): 48-64.

Cherunya PC, Ahlborg H and Truffer B (2020) Anchoring innovations in oscillating domestic spaces: Why sanitation service offerings fail in informal settlements. Research Policy 49(1): 103841.

Cities-Alliance (2019) Slum Upgrading. Online, https://www.citiesalliance.org/About-slumupgrading\#Why is slum upgrading important.

Corburn J and Sverdlik A (2019) Informal settlements and human health. Integrating Human Health into Urban and Transport Planning. Springer, pp.155-171.

De Geest F (2016) Redeveloped Houses: Contextualizing the experiences of slum improvement in Nagpur within global dynamics and local complexities. Universiteit Gent, Gent.

De Haan L and Zoomers A (2005) Exploring the frontier of livelihoods research. Development and Change 36(1): 27-47.

Fullilove MT (2016) Root shock: How tearing up city neighborhoods hurts America, and what we can do about it. New Village Press.

Geiser U, Müller-Böker U and Babar Shahbaz B (2011) 12 Towards an Analytical Livelihoods Perspective in Critical Development Research. Research for Sustainable Development. 257.

Gomersall K (2018) Resettlement practice and the pathway to the urban ideal. Geoforum 96: 51-60. 
Gulyani S and Bassett EM (2007) Retrieving the baby from the bathwater: slum upgrading in SubSaharan Africa. Environment and Planning C: Government and Policy 25(4): 486-515.

Hargreaves T, Longhurst N and Seyfang G (2013) Up, down, round and round: connecting regimes and practices in innovation for sustainability. Environment and Planning A 45(2): 402-420.

Huchzermeyer M (2009) The struggle for in situ upgrading of informal settlements: a reflection on cases in Gauteng. Development Southern Africa 26(1): 59-73.

Imparato I and Ruster J (2003) Slum upgrading and participation: Lessons from Latin America. The World Bank.

Iweka AC and Adebayo AK (2015) Global slum upgrading practices: identifying the contemporary challenges. Journal of Construction Project Management and Innovation 5(1): 1034-1044.

Keivani R and Werna E (2001) Modes of housing provision in developing countries. Progress in planning 55(2): 65-118.

Khalifa MA (2015) Evolution of informal settlements upgrading strategies in Egypt: From negligence to participatory development. Ain Shams Engineering Journal 6(4): 1151-1159.

KNCHR (2018) Allocation of housing units in Kibera Soweto East Zone ' $A$ ' redevelopment project under the Kenya Slum Upgrading Programme. Reportno. Report Number|, Date. Place Published|: Institution |.

Lewis C (2017) Turning houses into homes: Living through urban regeneration in East Manchester. Environment and Planning A 49(6): 1324-1340.

Long N (1997) Agency and constraint, perceptions and practices. A theoretical position. Images and realities of rural life. Wageningen perspectives on rural transformations. van Gorcum, pp.120.

MacPherson L (2013) Participatory approaches to slum upgrading and poverty reduction in African cities. Hydra-Interdisciplinary Journal of Social Sciences 1(1): 85-95.

Majale M (2001) Towards pro-poor regulatory guidelines for urban upgrading. A review of papers presented at the International Workshop on Regulatory Guidelines for Urban Upgrading held at Bourton-on-Dunsmore. 17-18.

Margalit T and Kemp A (2019) The uneven geographies of post-political planning: Objections to urban regeneration projects in peripheral and central Israeli cities. Environment and Planning A: Economy and Space. $0308518 \times 18819003$.

Matamanda AR (2019) Battling the informal settlement challenge through sustainable city framework: experiences and lessons from Harare, Zimbabwe. Development Southern Africa. 1-15.

Meikle S, Ramasut T and Walker J (2001) Sustainable urban livelihoods: Concepts and implications for policy.

Meredith T and MacDonald M (2017) Community-supported slum-upgrading: Innovations from Kibera, Nairobi, Kenya. Habitat International 60: 1-9.

Mesplé-Somps S, Pasquier-Doumer L and Guénard C (2016) Do slum upgrading programmes improve living standards? Evidence from Djibouti. Reportno. Report Number|, Date. Place Published|: Institution|.

Minnery J, Argo T, Winarso H, et al. (2013) Slum upgrading and urban governance: Case studies in three South East Asian cities. Habitat International 39: 162-169.

Mitra S, Mulligan J, Schilling J, et al. (2017) Developing risk or resilience? Effects of slum upgrading on the social contract and social cohesion in Kibera, Nairobi. Environment and Urbanization 29(1): 103-122.

Morrison N (2017) Playing by the rules? New institutionalism, path dependency and informal settlements in Sub-Saharan Africa. Environment and Planning A: Economy and Space 49(11): 2558-2577.

Moser CO (1998) The asset vulnerability framework: reassessing urban poverty reduction strategies. World Development 26(1): 1-19.

Napier M (2007) Informal settlement integration, the environment and sustainable livelihoods in subSaharan Africa. Council for Scientific \& Industrial Research in South Africa. 
Rigon A (2014) Building local governance: participation and elite capture in slum-upgrading in Kenya. Development and Change 45(2): 257-283.

Sakdapolrak P (2014) Livelihoods as social practices. Re-energising livelihoods research with Bourdieu's theory of practice. Geographica Helvetica 69(1): 19-28.

Samndong R (2018) The participation illusion: questioning community participation in a REDD+ pilot project in the Democratic Republic of Congo. International Forestry Review 20(3): 390-404.

Scoones I (1998) Sustainable rural livelihoods: a framework for analysis.

Shove E, Pantzar M and Watson M (2012) The dynamics of social practice: everyday life and how it changes. Sage Publications.

Shove E and Walker G (2007) CAUTION! Transitions ahead: politics, practice, and sustainable transition management. Environment and Planning A 39(4): 763-770.

Small L-A (2007) The sustainable rural livelihoods approach: a critical review. Canadian Journal of Development Studies/Revue canadienne d'études du développement 28(1): 27-38.

Smith TA and Brown A (2019) Community-led housing and urban livelihoods: Measuring employment in low-income housing delivery. Habitat International. 102061.

Solesbury W (2003) Sustainable livelihoods: A case study of the evolution of DFID policy. Overseas Development Institute London.

Thieme S (2008) Sustaining livelihoods in multi-local settings: possible theoretical linkages between transnational migration and livelihood studies. Mobilities 3(1): 51-71.

Tissington K (2012) Informal settlement upgrading in South Africa: linkages to livelihood creation, informal sector development and economic opportunity generation.

Turley R, Saith R, Bhan N, et al. (2013) Slum upgrading strategies involving physical environment and infrastructure interventions and their effects on health and socio-economic outcomes. Cochrane Database Syst Rev 1(1).

UN-DESA (2018) World Urbanization Prospects: The 2018 Revision. Population Division, Department of Economic and Social Affairs, United Nations Secretariat.

UN-Habitat (2007) UN-HABITAT and the Kenya Slum Upgrading Programme. Reportno. Report Number|, Date. Place Published|: Institution|.

UN-Habitat (2015) Habitat III Issue Paper 22-Informal Settlements. New York: UN Habitat.

Wesselink A, Paavola J, Fritsch O, et al. (2011) Rationales for public participation in environmental policy and governance: practitioners' perspectives. Environment and Planning A 43(11): 2688-2704.

Williams G, Devika J and Aandahl G (2015) Making space for women in urban governance? Leadership and claims-making in a Kerala slum. Environment and Planning A 47(5): 11131131. 